\title{
NNPID-based Stator Voltage Oriented Vector Control for DFIG based Wind Turbine Systems
}

\author{
Shanzhi LI ${ }^{1}$, Haoping WANG ${ }^{1}$, Yang TIAN ${ }^{1}$, Nicolai CHRISTOV ${ }^{2}$, Abdel AITOUCHE ${ }^{2}$ \\ ${ }^{1}$ Sino-French International Joint Laboratory of Automatic Control and Signal Processing (LaFCAS), \\ Nanjing University of Science \& Technology (NUST), \\ Nanjing 210094, China; \\ 2 LAGIS- CNRS UMR 8219, LaFCAS, University Lille Nord de France, \\ Lille France, 59600
}

\begin{abstract}
Doubly fed induction generators are widely adopted for the wind turbine systems since it is cheap and reliable. Based on the traditional stator voltage oriented vector control method, the performance of the proposed vector control is largely influenced by the variations of the DFIG parameters. And the classical PID algorithm cannot achieve the maximum power point tracking (MPPT) in time (owing to the transient wind). Hence, in this paper, to eliminate parameters variations on the power output and capture the MPPT rapidly, we propose a stator voltage oriented vector control which is based on a Neural Network PID (NNPID) technology. The weights which are being similar to the PID coefficients are adapted by Hebb rule to decrease the power error online according to the error gradient descent method, while the classical PID coefficients will be a constant. The effectiveness of the proposed method is demonstrated by corresponding simulation results: even in the case of wind mutation change, the proposed NNPID can track the variation of the wind energy, and robust to the DFIG parameters variations.
\end{abstract}

Keywords: wind turbine system; maximum power point tracking; DFIG; NNPID;

\section{Introduction}

As a renewable and clean energy, wind energy which growths rapidly worldwide and attracts widespread attention by governments [1]. Recently, high efficiency and low cost power production control methods and technologies are always an eternal working goal for researchers and engineers.

Doubly fed induction generators (DFIG) which are widely adopted for the wind turbine systems occupy most parts of the global market because of the lower-cost and smaller inverter capacity. However, the DFIG's characteristics of non-linearties, strong coupling, and varying parameters as well as the wind randomness are intractable problems. It also reduces the efficiency of the wind energy. Moreover, the model of wind is complicated, and affected by many factors. Besides, dynamic and static characteristics of nature wind need to be reflected by the wind model. And wind turbine system also requires an appropriate wind model for different performances. The emitted power usually cannot catch up with capture wind energy because of both the transient wind and the lag inertia of the blades. Considering wind uncertainties and wind turbine systems nonlinearities, it is difficult to selecting appropriate classical PID coefficients to obtain good performances. In addition, these coefficients usually maintain constant once the PID controller is installed. Recently, artificial intelligent controls have been developed rapidly and applied gradually to wind turbine systems, such as neural network control and fuzzy control are discussed in [2-4]. However, to achieve good control performance needs complex computations in the neural network based control algorithms. A rule table for fuzzy control is also difficult to design [6]. For fuzzy controllers which select this rule table by self-adjusting needs to spend a longer time in calculations.

In this paper, to improve the efficiency of capturing wind energy and simplify the referred control methods computations, a particular PID controller which is based on a single-neuron network is developed and called Neural Network PID (NNPID). Known that three layers of neural networks (NNs) can be used to approximate an arbitrary input-output mapping [7]. The weights of the proposed NNPID can be adjusted adaptively online with tracking errors. This used adaptive mechanism is useful to overcome both the wind turbine systems external disturbances and parameters uncertainties.

The rest paper is organized as follows: a wind model is presented in $2^{\text {nd }}$ section. And in $3^{\text {rd }}$ section, a wind turbine model which includes an aerodynamic model of the wind turbine rotor, DFIG model and drive trains model is 
described. After that, for the considered system, a fundamental stator voltage oriented vector control method and a NNPID controller is developed in $4^{\text {th }}$ section. Then to validate the proposed method, some numerical simulation results are illustrated in $5^{\text {th }}$ section. Finally, some conclusion remarks are presented in 6th section.

\section{Wind Model}

A natural wind which is a dynamic stochastic process can be mainly divided into two categories. The first one which builds by the meteorological data such as location information and altitude is applied for largescale wind farm and forecasting wind speed. The second one which is developed on probability and statistics methods is called as a statistical model [8]. In this paper, the statistical model is used and can be defined as follow

$v=v_{s}+v_{r}$

where, $v_{s}$ is the average component, which reflects the wind speed long-term characteristic and maintains constant, $v_{r}$ is the turbulence component, and it is related to the turbulence intensity which depends upon the roughness of a wind farm surface. The von Karman's or Van der Hoven's models are used to express the dynamic turbulence characteristics [9]. Because of the major drawback, that the turbulence component is regarded as a stationary random process which cannot reflect the complete wind information by using the Van der Hoven's model. As a result, the von Karman's model is chosen. In this model, the non-stationary turbulence component can be simulated by the following shaping filter which is defined as:

$$
H_{t}(s)=K_{F} \frac{0.4 T_{F} s+1}{\left(T_{F} s+1\right)\left(0.25 T_{F} s+1\right)}
$$

where parameters of $K_{F}$ and $T_{F}$ are decided by the average component. And the input of the shaping filter is a white noise. Hence the turbulence component $v_{r}$ can be deduced as:

$v_{r}(t)=\frac{1}{2 \pi} \int H_{t}(s) \varepsilon(s) e^{s t} d s$

where $\varepsilon(s)$ represents a zero mean white noise signal.
Generally, the above wind model can be used to simulate approximately a real wind. However, in order to demonstrate the following proposed control methods performances, some extreme wind cases are also tested, such as signals of step or ramp type.

\section{Wind Turbine and Driver Train Models}

\subsection{Wind turbine rotor model}

The wind turbine will absorb part of energy when the airflow runs through it [10]. And the available captured power can be represented as

$P=\frac{1}{2} C_{P}(\lambda, \beta) \pi R^{2} \rho v^{3}$

$C_{P}(\lambda, \beta)=0.5176\left(\frac{116}{\lambda_{i}}-0.4 \beta-5\right) e^{\frac{-21}{\lambda_{i}}}$

$\frac{1}{\lambda_{i}}=\frac{1}{\lambda+0.08 \cdot \beta}-\frac{0.035}{\beta^{3}+1}$

where $\mathrm{R}$ is the radius of wind turbine, $\rho$ is the air density, $C_{P}(\lambda, \beta)$ is the power coefficient, $\lambda=\omega_{T} R / v$ is the tip speed ratio, $\omega_{T}$ is the angular speed for the wind wheel, and $\beta$ is the pitch angle. Cp is affected by both $\lambda$ and $\beta$. When the wind overrides the rated wind, the capture power will exceed its capacity. So in the field, the pitch angle will be adapted to maintain a constant rated power. The output torque on the wind turbine is represented as

$T_{L}=P / \omega_{T}$

\subsection{The drive train model}

To simplify wind drive train model and fulfil the control requirements, we choose a one-mass model [11]. When the stiffness and the damping factor are neglected, its corresponding motion equation is described as:

$T_{L}-T_{e}=\frac{J}{n_{p}} \frac{d \omega_{r}}{d t}=\frac{J}{n_{P}} \frac{d^{2} \theta}{d t^{2}}$

where $T_{e}$ is the generator torque, $T_{L}$ is the wind turbine torque which equals to the torque of generator side, $J$ is the equivalent moment inertia, $n_{p}$ is the number of pole pairs, $\omega_{r}$ is the rotor electrical angular speed, and $\theta$ is the rotor position angle of DFIG. 


\subsection{DFIG model}

In the motor reference frame as in [12-13], the dynamic equations of DFIG can be developed by vector transformation dq-axis voltage and flux equations as follows

$$
\begin{aligned}
& \left\{\begin{array}{l}
\vec{u}_{s}=R_{s} \vec{i}_{s}+j \omega_{s} \vec{\Psi}_{s}+p \vec{\Psi}_{s} \\
\vec{u}_{r}=R_{r} \vec{i}_{r}+j \omega_{s l} \vec{\Psi}_{r}+p \vec{\Psi}_{r}
\end{array}\right. \\
& \left\{\begin{array}{l}
\vec{\psi}_{s}=L_{s} \vec{i}_{s}+L_{m} \vec{i}_{r} \\
\vec{\psi}_{r}=L_{r} \vec{i}_{r}+L_{m} \vec{i}_{s}
\end{array}\right.
\end{aligned}
$$

where $L_{m}$ is the mutual inductance, $L_{s}$ is the stator self-inductance, $L_{r}$ the rotor selfinductance, $R_{s}$ and $R_{r}$ are the stator and rotor resistances, $\omega_{s}$ is the angular frequency of the grid, $\omega_{s l}=\omega_{s}-\omega_{r}$ is the slip angular frequency, and $u_{s q}, u_{s d}, u_{r q}$ and $u_{r d}$ are stator and rotor voltages in the dq reference frame. And

$$
\begin{aligned}
& \vec{u}_{r}=u_{r d}+j u_{r q}, \\
& \vec{u}_{s}=u_{s d}+j u_{s q}, \\
& \vec{i}_{s}=i_{s d}+j \cdot i_{s q}, \\
& \vec{i}_{r}=i_{r d}+j \cdot i_{r q}, \\
& \vec{\psi}_{s}=\psi_{s d}+j \psi_{s q}, \\
& \vec{\psi}_{r}=\psi_{r d}+j \psi_{r q} .
\end{aligned}
$$

\section{Design of NNPID Controller}

In this section for the considered DFIG model, we propose a stator voltage oriented vector control which is based on a Neural Network PID (NNPID) technology to track the available maximum power. Its control architecture is illustrated in Figure 1.

Under this scheme, firstly the rotor dq axis current references which are used for optimal power tracking are calculated from the active and reactive power. They are decoupled by the following referred stator voltage oriented vector control. Then, with the application of the proposed NNPID, one ensures the maximum output power tracking.

\subsection{Stator voltage oriented vector control method}

According to the magnetic flux conservation principle, the DFIG three-phase dynamic model can be simplified into a two-phase dp dynamic model. Without the proposed stator voltage oriented vector control [14], the calculated flux are easily affected by generator parameters, such as inductance cannot be accurately obtained.

Thus under stator voltage reference frame, one obtains

$$
\left\{\begin{array}{l}
u_{s q}=0 \\
u_{s d}=u_{s}
\end{array}\right.
$$

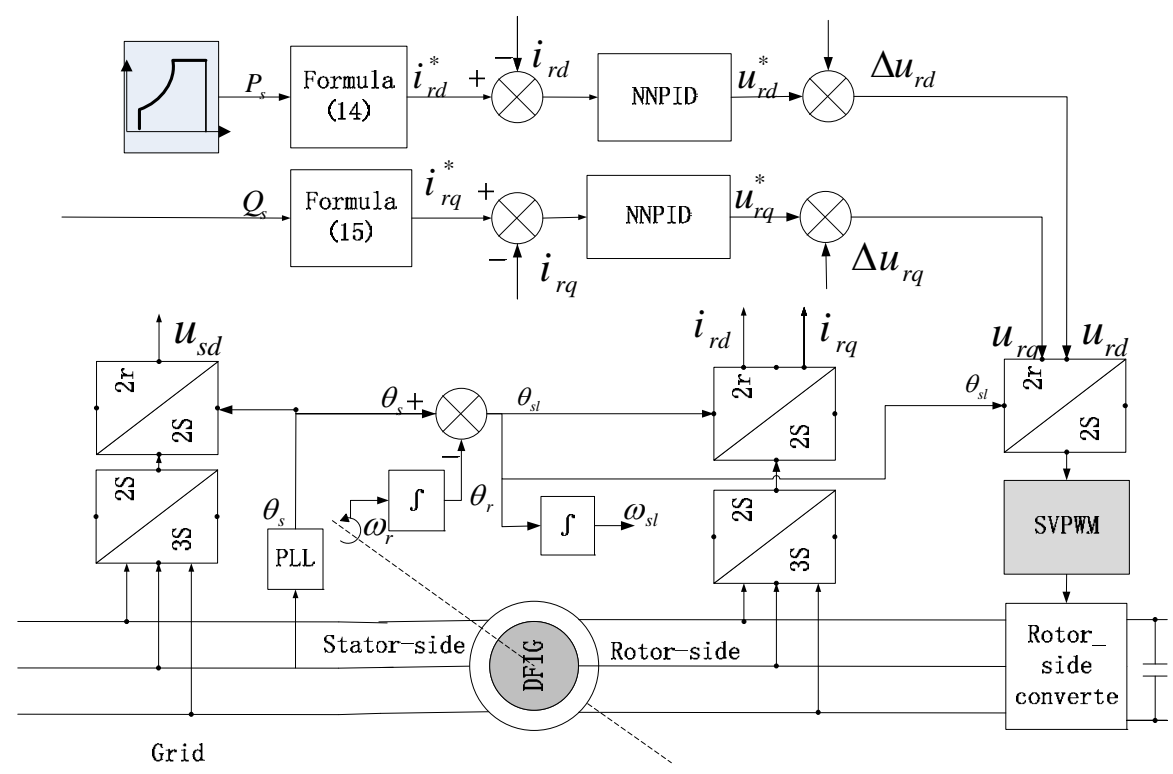

Figure 1. Structure of stator voltage oriented vector control based on NNPID 
where $u_{s d}$ and $u_{s q}$ are voltages under $d q$-axis.

In wind turbine systems, the wind energy is mainly transferred to power through the stator side to grid. When the DFIG runs on the state of super-synchronous condition, a part of power will flow across the rotor-side converter. In steady-state working condition, the stator resistance can be ignored which means $R_{s}<<\omega_{s} L_{s}$. And according to power equation, the following active and reactive power can be calculated as follows

$$
\begin{aligned}
& P_{s}=-\frac{3}{2}\left(u_{s d} i_{s d}+u_{s q} i_{s q}\right) \approx-\frac{3}{2} \frac{L_{m}}{L_{s}} u_{s} i_{r d} \\
& Q_{s}=-\frac{3}{2}\left(u_{s d} i_{s q}-u_{s q} i_{s d}\right) \approx \frac{3}{2}\left(\frac{L_{m}}{L_{s}} u_{s} i_{r q}+\frac{u_{s}^{2}}{\omega_{s} L_{s}}\right)
\end{aligned}
$$

Thus from the above equations, the following current references of $i_{r d}^{*}$ and $i_{r q}^{*}$ can be calculated as

$$
\begin{aligned}
& i_{r d}{ }^{*} \approx-\frac{2 L_{s}}{3 u_{s} L_{m}} P^{*} \\
& i_{r q}{ }^{*}=\frac{2 L_{s}}{3 u_{s d} L_{m}} Q^{*}-\frac{u_{s}}{\omega_{s} L_{m}}
\end{aligned}
$$

The reactive power reference $Q^{*}$ which can be adapted with variation values of grid is selected to be 'zero' here. And it is important to note that the active power reference $P^{*}$ which is calculated from the wind turbine optimal power curve (illustrated in Figure 2) can be easily obtained with measurements of rotor angular speed.

Substituting (10) and (11) in (9), the $d p$-axis compensated voltages can be calculated as

$$
\begin{aligned}
& \Delta u_{r d}=-\omega_{s l}\left(L_{r} \sigma i_{r q}+\frac{L_{m}}{L_{r}} \frac{u_{s}}{\omega_{s}}\right) \\
& \Delta u_{r q}=\omega_{s l} L_{r} \sigma i_{r d}
\end{aligned}
$$

with the leakage factor $\sigma=1-L_{m}^{2} / L_{s} L_{r}$.

Hence the input of SVPWM convertor can be presented as

$u_{r d}=u_{r d}^{*}+\Delta u_{r d}$

$u_{r q}=u_{r q}^{*}+\Delta u_{r q}$

where $u_{r d}^{*}$ and $u_{r q}^{*}$ are reference voltages which are calculated by the NNPID and described in the next subsection.

\subsection{Neural Network PID}

Traditionally, a classic PID controller performances whose three coefficient values are difficult to select are normally affected by systems nonlinearities and external disturbances [15]. Thus in this subsection, a Neural Network PID (NNPID) which presents self-learning and adjusting abilities on coefficient weights online is developed[16]. Here the detailed of designing d-axis NNPID is

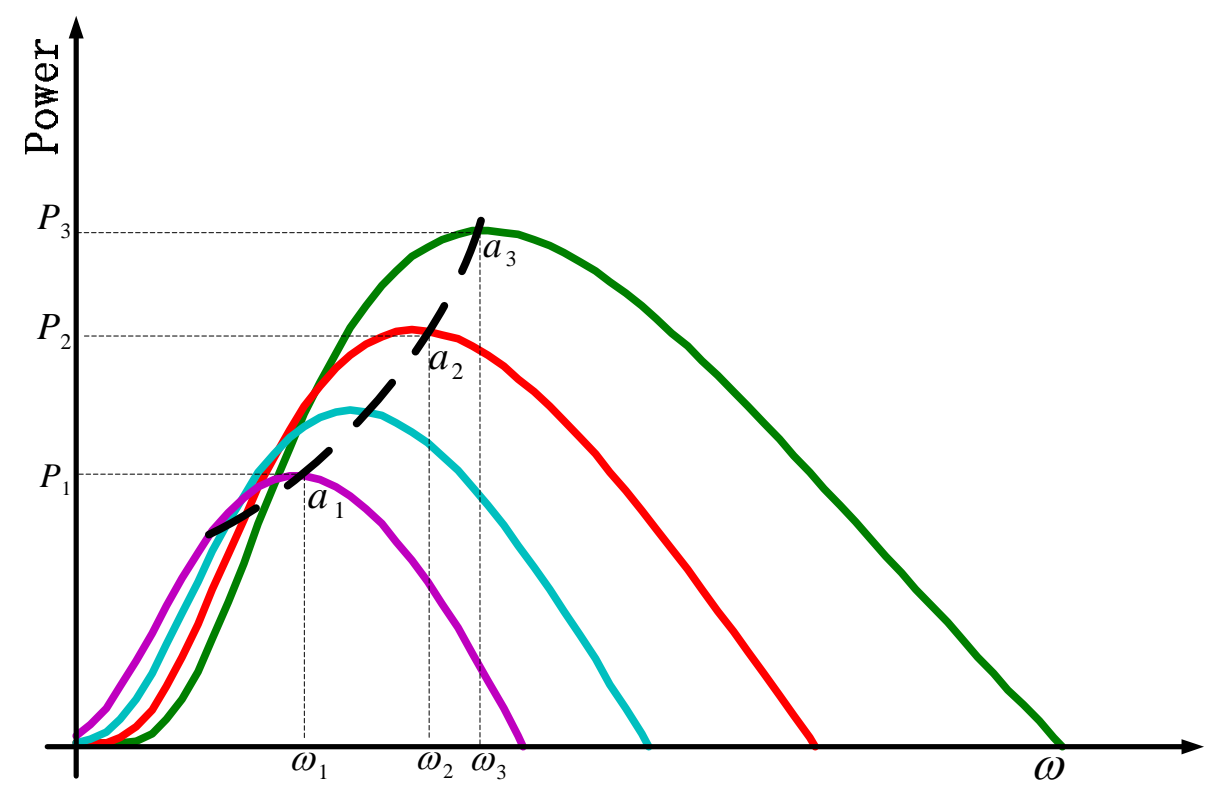

Figure 2. Optimal wind turbine power curve 


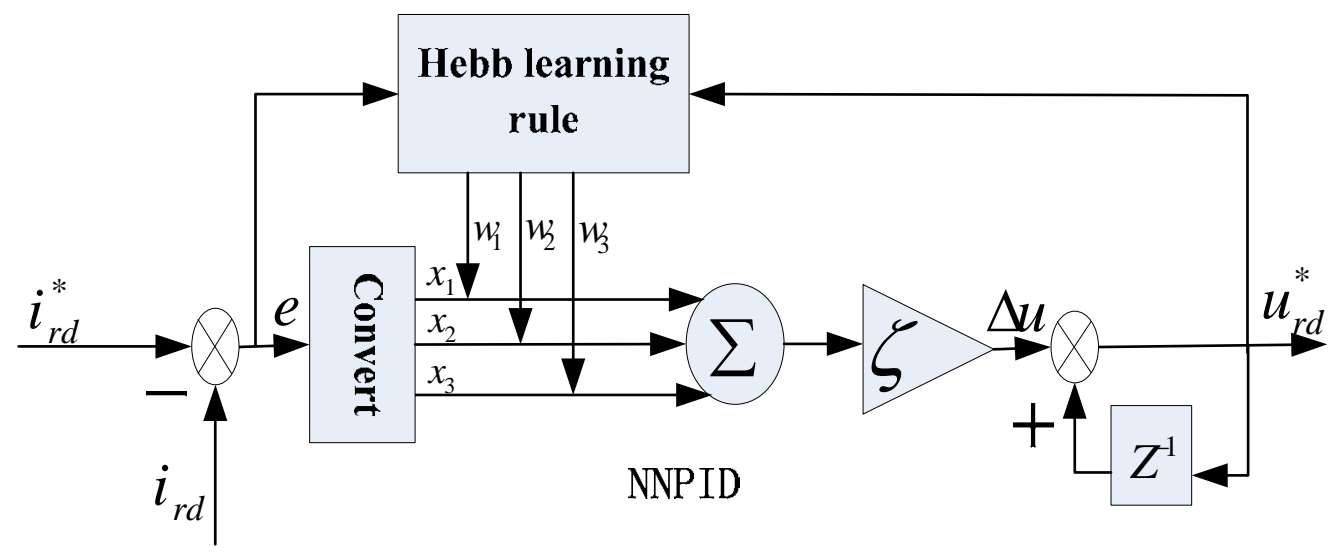

Figure 3. Structure of NNPID

only presented because the q-axis one is similarly to d-axis.

The input of NNPID in d-axis is the current error $e_{r d}(k)=i_{r d}^{*}(k)-i_{r d}(k)$. The output of NNPID is the d-axis voltage $u_{r d}(k)$, which is illustrated in Figure 3.

The output of NNPID can be written as follow

$u_{r d}^{*}(k)=u_{r d}^{*}(k-1)+\zeta \sum_{i=1}^{3} x_{i}(k) w_{i}(k)$

where $\zeta$ is the proportion coefficient which relates to the stability of the closed-loop system, and the coefficients of $w_{1}, w_{2}$ and $w_{3}$ are represents the proportional, integral and differential constants for a classical incremental discrete PID controller. $x_{i}(k)$ is the error polynomials and written as follows

$$
\left\{\begin{array}{l}
x_{1}(k)=e_{r d}(k)-e_{r d}(k-1) \\
x_{2}(k)=e_{r d}(k) \\
x_{3}(k)=e_{r d}(k)-2 e_{r d}(k-1)+e_{r d}(k-2)
\end{array}\right.
$$

In this paper, the error function is defined as

$$
E=\frac{1}{2} e_{r d}(k)^{2}=\frac{1}{2}\left(i_{r d}^{*}-i_{r d}\right)^{2}
$$

According to the Hebb learning rule [17] and avoiding local minima[18], an improved algorithm for adjusting the weights is proposed and deduced as follows

$$
\left\{\begin{array}{l}
w_{i}(k)=w_{i}(k-1)+\Delta w_{i}(k)+\alpha_{i}(w(k-1)-w(k-2)) \\
\Delta w_{i}(k)=-\eta e_{r d}(k) u_{r d}(k) X_{i}(k)
\end{array}\right.
$$

where $\eta_{i}$ is the learning factor, $e(k)$ is equal to the error between the reference and measurements, and $\alpha_{i}$ is the inertia coefficient. In the summary, the NNPID algorithm can be shown in Figure 4.

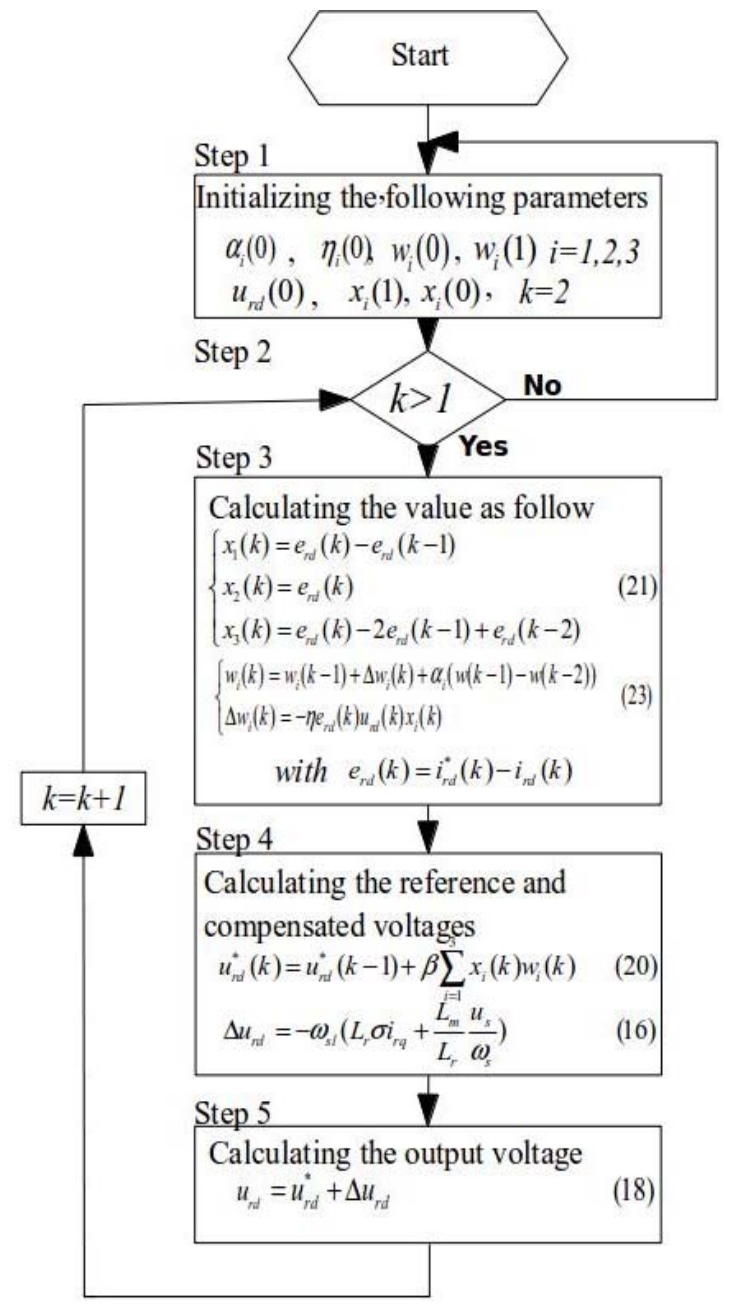

Figure 4. NNPID process algorithm 


\section{Numerical Simulation}

In this section, we validate the proposed NNPID based control strategy for the considered wind turbine system on Matlab/Simulink. The controlled system parameters are shown in Table 1.

Table 1. Parameters of the wind turbine system

\begin{tabular}{|c|c|}
\hline Parameter & Value \\
\hline Blade radius & $40 \mathrm{~m}$ \\
\hline Rated Power & $1.5 \mathrm{MW}$ \\
\hline air density & $1.25 \mathrm{~kg} / \mathrm{m}^{3}$ \\
\hline Rated Voltage & $690 \mathrm{~V}$ \\
\hline Frequency & $50 \mathrm{~Hz}$ \\
\hline Number of poles pair & 2 \\
\hline Stator resistance & $1.1 \mathrm{~m} \Omega$ \\
\hline Rotor resistance & $2.3 \mathrm{~m} \Omega$ \\
\hline Stator leakage inductance & $0.007 \mathrm{mH}$ \\
\hline Rotor leakage inductance & $0.0075 \mathrm{mH}$ \\
\hline Stator-rotor mutual inductance & $2.9936 \mathrm{mH}$ \\
\hline Wind turbine moment of inertia & $4.95 \mathrm{M}$ \\
$\mathrm{kg} \cdot \mathrm{m}^{2}$ \\
\hline Generator moment of inertia & $90 \mathrm{~kg} \cdot \mathrm{m}^{2}$ \\
\hline Gearbox ratio & 83.53 \\
\hline
\end{tabular}

To demonstrate the proposed controller performance, we consider an external wind input signal which contains mainly three different types of step, ramp and stochastic signal and illustrated in Figure. 5. In addition, to validate the robustness of NNPID, the stator resistance is selected for changing at $7.5^{\text {th }}$ second from the value of $R_{s}$ to $1.2 * R_{s}$. Because its value is easily changed with the variation of temperature. Under these testing conditions and without considering the wind turbine system linked to the grid, their corresponding control results which includes the power coefficient, rotor speed, reference and actual power, and tracking error are illustrated respectively in Figure 5 to Figure 9.

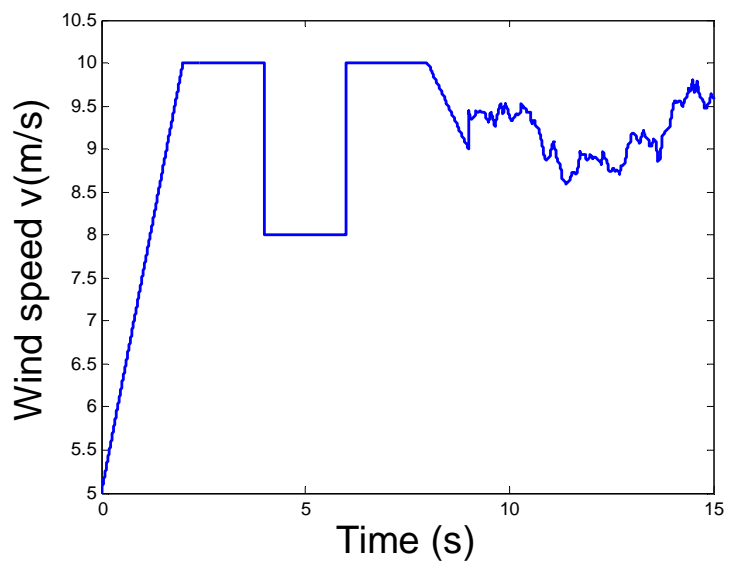

Figure 5. Evolution of the wind speed parameter

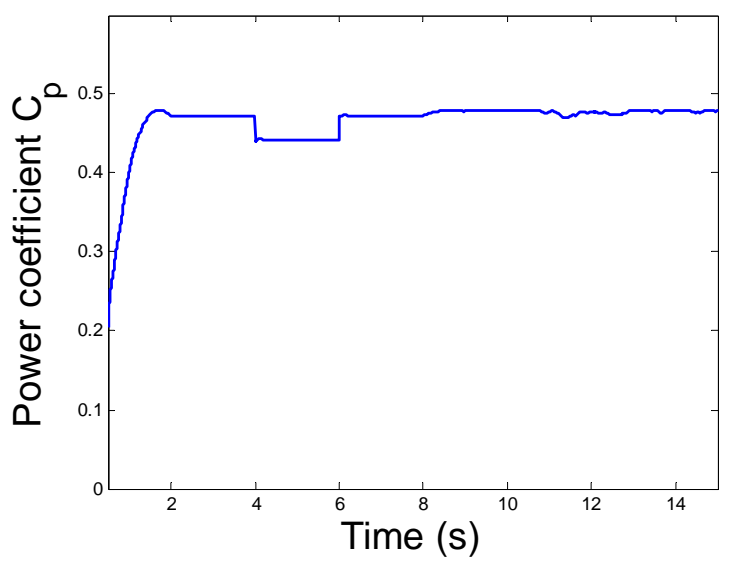

Figure 6. Power coefficient

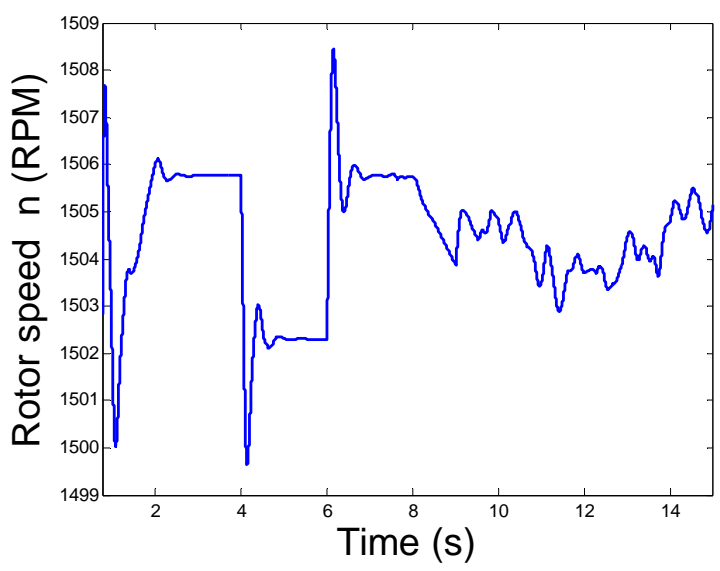

Figure 7. Rotor speed

It is important to note that, from Figure. 8 and Figure. 9, with the proposed NNPID technology, the actual power output tracks very well the available maximal power point, even under the variation of wind speed and system parameter variations. 


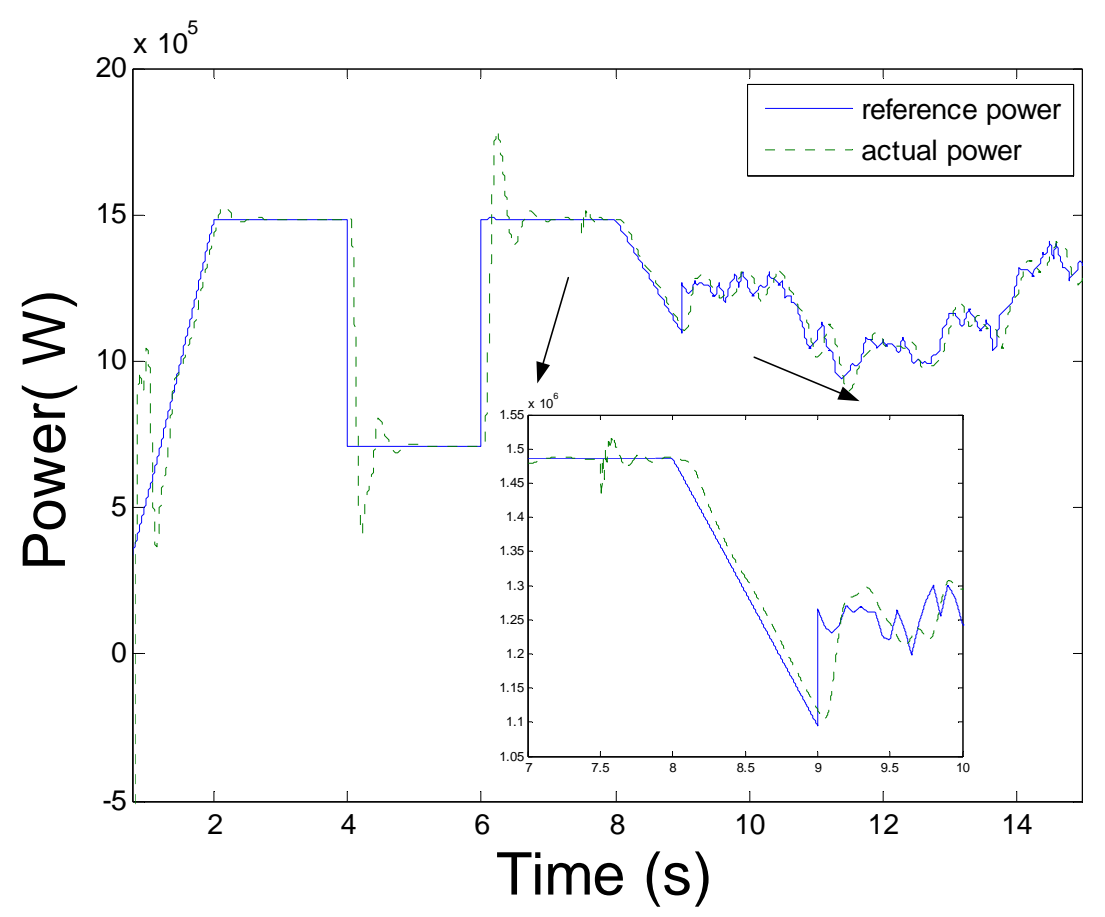

Figure 8. Reference and actual power

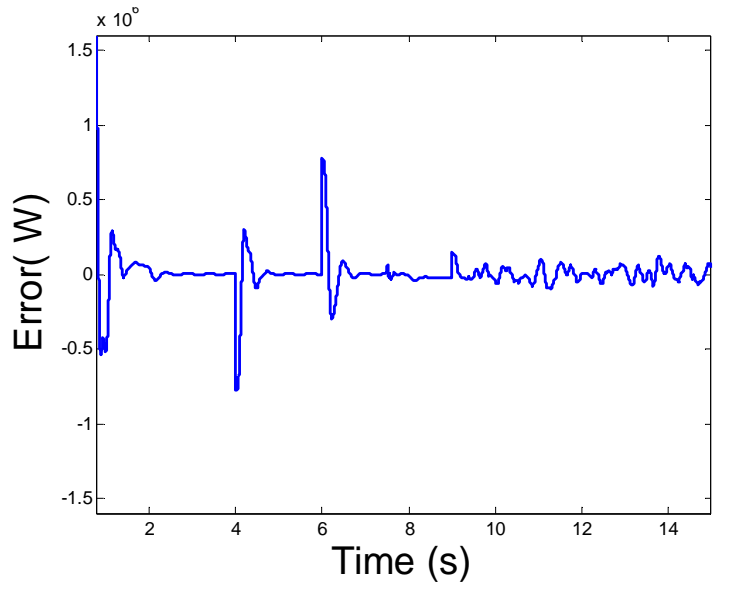

Figure 9. Power error between reference and actual power

\section{Conclusion}

In this paper, a NNPID based stator voltage oriented vector control is designed and implemented to a DFIG based wind turbine system. The advantages of the proposed control are that its corresponding control weights can be adapted online by Hebb rule by according to power error. And the effectiveness of the proposed method is demonstrated by corresponding numerical simulation results, even in cases of wind mutation changes.

\section{REFERENCES}

1. IZADIAN, A., N. GIRRENS, P. KHAYYER, Renewable Energy Policies: A Brief Review of the Latest U.S. and E.U. Policies, Industrial Electronics Magazine, IEEE, vol. 7(3), 2013, pp. 21-34.

2. JAFARNEJADSANI, H., J. PIEPER, J. EHLERS, Adaptive Control of a Variable-Speed Variable-Pitch Wind Turbine Using Radial-Basis Function Neural Network, Control Systems Technology, IEEE Transactions on, vol. 21, no. 6, 2013, pp. 2264-2272.

3. QINGSONG, L., Y. YUFEI, W. JUNXIAO, Simulation and Application of Neural Network PID Auto-Tuning Controller in Servo-System, Database Technology and Applications (DBTA), 2nd International Workshop, 2010, pp. 1-4.

4. PHAN QUOC, D., B. ANH NGUYEN, L. HONGHEE, New Artificial Neural Network based Direct Virtual Torque Control and Direct Power Control for DFIG in Wind Energy Systems, Power Electronics and Drive Systems (PEDS), 2011 IEEE Ninth International Conference on, 2011, pp. 219-227. 
5. ZHIMING, Y., W. XIAORONG, Fuzzy PID Control of Induction Generators, Cognitive Informatics \& Cognitive Computing (ICCI*CC), 10th IEEE Intl. Conference, 2011, pp. 130-134.

6. ABDELHADY, F., S. ABUELENIN, Design and Simulation of a Fuzzysupervised PID Controller for a Magnetic Levitation System, Studies in Informatics and Control, vol. 17, no. 3, 2008, pp. 315-328.

7. SIFAOUI, A., A. ABDELKRIM, S. ALOUANE, On New RBF Neural Network Construction Algorithm for Classification, Studies in Informatics and Control, vol. 18, no. 2, 2009, pp. 103-110.

8. KAREEM, A., Numerical Simulation of Wind Effects: a Probabilistic Perspective, Journal of Wind Engineering and Industrial Aerodynamics, vol. 96, no. 10, 2008, pp. 1472-1497.

9. NICHITA, C., D. LUCA, B. DAKYO, Large band Simulation of the Wind Speed for Real Time Wind Turbine Simulators, Energy Conversion, IEEE Trans., vol. 17, no. 4, 2002, pp. 523-529.

10. MIHETPOPA, L., F. BLAABJERG, I. BOLDEA, Wind Turbine Generator Modeling and Simulation Where Rotational Speed is the Controlled Variable, Industry Applications, IEEE Trans., vol. 40, no. 1, 2004, pp. 3-10.

11. TAPIA, A., G. TAPIA, J. X. OSTOLAZA, Modeling and Control of a Wind Turbine driven Doubly fed Induction Generator, Energy Conversion, IEEE Trans., vol. 18, no. 2, 2003, pp. 194-204.

12. JIABING, H., H. NIAN, H. XU, Dynamic Modeling and Improved Control of DFIG under Distorted Grid Voltage Conditions, Energy Conversion, IEEE Trans., vol. 26, no. 1, 2011, pp. 163-175.
13. YAZHOU, L., A. MULLANE, G. LIGHTBODY., Modeling of the Wind Turbine with a Doubly Fed Induction Generator for Grid Integration Studies, Energy Conversion, IEEE Transactions on, vol. 21, no. 1, 2006, pp. 257-264.

14. IDJDARENE, K., D. REKIOUA, T. REKIOUA, Vector Control of Autonomous Induction Generator taking Saturation Effect into Account, Energy Conversion and Management, vol. 49, no. 10, 2008, pp. 2609-2617.

15. PAN, G., M. ZHANG, Q. F. LI, Power Control of DFIG Based on the Nonlinear PID, Wei-Te Dianji (Small \& Special Electrical Machines), vol. 41, no. 1, 2013, pp. 50-53.

16. XINGJIA, Y., W. HEXU, D. YING, Research on Rotor Excitation Neural Network PID Control of Variable Speed Constant Frequency Wind Turbine, Intl. Conference on Electrical Machines and Systems,. ICEMS, 2007, pp. 560-565.

17. GE, S., C. C. HANG, T. H. LEE, Stable Adaptive Neural Network Control: Springer Publishing Company, Incorporated, 2010.

18. MARABA, V. A., A. E. KUZUCUOGLU, Speed Control of an Asynchronous Motor using PID Neural Network, Studies in Informatics and Control, vol. 20, no. 3, 2011, pp. 199-208.

19. PINTEA, A., H. P. WANG, N. CHRISTOV, D. POPESCU, P. BORNE, Modeling and Power Regulation of Horizontal Variable Speed Wind Turbines, Studies in Informatics and Control, vol. 20, no. 3, 2011, pp. 305-312.

20. WANG, H. P., A. PINTEA, N. CHRISTOV, P. BORNE, Modelling and Recursive Power Control of Horizontal Variable Speed, Control Engineering And Applied Informatics, vol.14, no. 4, 2012, pp. 33-41. 